\title{
Una reseña acerca de "Manual de morfosintaxis: una propuesta de análisis del lenguaje desde la fonoaudiología"
}

Carlos Álvarez ${ }^{\mathbf{a}, \mathbf{b}}$

a Departamento de Fonoaudiología, Universidad de Chile, Chile

b Grupo de Investigación Koiné, Universidade de Santiago de Compostela, España

Email: calvarez8@uchile.cl

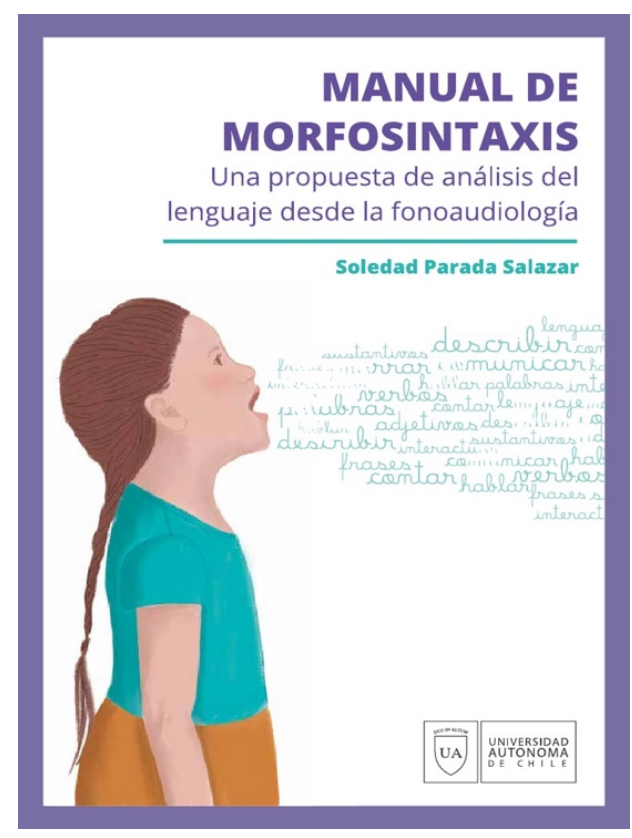

Autor/a: Soledad Parada Salazar

Año: 2019

ISBN (versión digital): 978-956-8454-54-8

Editorial: Centro de Comunicación de las Ciencias, Universidad Autónoma de Chile

La publicación de un manual de análisis de la morfosintaxis del español no pasa inadvertida entre aquellos que dedican su atención a uno de los fenómenos que nos distingue como especie, y que nos acompaña en nuestro diario vivir: el lenguaje. En el ámbito de la fonoaudiología, la morfosintaxis es un área que concita notable interés, debido a la afectación que en esta ocasionan síndromes, trastornos y enfermedades de diversa naturaleza. Así, la morfosintaxis en fonoaudiología ocupa un lugar prominente en los planes de estudio de los programas de pregrado, en el quehacer clínico-educativo y en las líneas de investigación consolidadas o emergentes. En este contexto, Manual de morfosintaxis: una propuesta de análisis del lenguaje desde la fonoaudiología, de la autora Soledad Parada Salazar, viene a contribuir con un material de orientación práctica dirigido, principalmente, a personas interesadas en el lenguaje infantil. Cabe destacar que el manual también podría ser utilizado como material de apoyo durante la formación de estudiantes, especialmente, de fonoaudiología.

Resulta interesante constatar que este manual ha sido elaborado bajo licencia Creative Commons, lo que garantiza, en este caso, el acceso sin costo monetario a su contenido. Las obras de acceso libre cimentan la recuperación del sentido público del conocimiento; por tanto, este manual representa una importante contribución a tan noble propósito.

Publicado en octubre de 2019 por el Centro de Comunicación de las Ciencias, de la Universidad Autónoma de Chile, el manual se organiza en cuatro secciones: Introducción, ¿Cómo elicitar una muestra de lenguaje?, Análisis morfosintáctico de muestras de lenguaje, Conclusión. Se suma a estas cuatro secciones el apartado con las fuentes bibliográficas consultadas.

En la primera sección, la autora ofrece los fundamentos teóricometodológicos que orientaron la confección del manual. Entre los fundamentos presentados, se evidencia un cúmulo de información que hilvana los argumentos que sustentan el llamado a incorporar, en los procesos evaluativos fonoaudiológicos, el análisis de muestras de lenguaje oral. Este llamado resulta ser bastante sugestivo debido a que, en cierta medida, remece el papel preponderante y canónico que han tenido las pruebas estandarizadas en la evaluación fonoaudiológica: "el análisis de muestras de lenguaje es primordial en la evaluación de la competencia lingüística de un niño o niña, pero debe ser complementado por test formales o tareas estructuradas que permitan elicitar y así analizar los elementos que no surgen en la 
muestra de lenguaje", declara la autora. Sin duda, un debate interesante y muy necesario.

Respecto de la segunda sección, titulada ¿Cómo elicitar una muestra de lenguaje?, la autora presenta, al inicio de esta, una breve revisión respecto de las principales actividades orientadas a incitar la producción de lenguaje oral en la población infantil. Además de la descripción de cada una de estas actividades, se discute sobre las características estructurales y cantidad de lenguaje que potencialmente un niño puede producir al realizar dichas actividades. Del mismo modo, en esta sección, la autora presenta información acerca de las características que debe tener una muestra representativa de lenguaje y entrega algunas directrices para su transcripción. Respecto de la primera parte de esta sección, cabe formular la siguiente observación: presentar las actividades de incitación de lenguaje oral "juego con juguetes", "tareas de descripción" y "narración de eventos", como métodos diferentes, puede ocasionar confusión en el lector. Esto motiva la formulación de las siguientes preguntas: ¿puede un niño realizar una descripción de un juguete que le interesa mientras juega de manera libre? ¿Puede un niño realizar una narración de eventos durante el juego libre con sus juguetes? Resulta evidente que la respuesta a ambas preguntas es sí. La razón reside en el hecho de que, en actividades de orden físico, como jugar con juguetes, es posible que el niño efectúe actos lingüístico-discursivos como la formulación de una descripción o narración. Por lo anterior, resulta conveniente, al momento de planificar las actividades para la obtención de lenguaje oral, tener claridad respecto de la diferencia entre actividades de orden físico y actos lingüísticodiscursivos. Da término a la segunda sección una descripción panorámica de los principales aspectos de la morfología y sintaxis del español. Esta descripción contiene un gran número de definiciones y ejemplos que pueden ser de gran utilidad para el lector que se está iniciando en el ámbito morfosintáctico.

La información entregada en las dos primeras secciones del manual pavimenta la ruta hacia la tercera sección, titulada Análisis morfosintáctico de muestras de lenguaje. En el inicio de esta, la autora establece que la muestra de lenguaje ya transcrita puede ser analizada de manera cualitativa o cuantitativa. El desarrollo de esta sección comienza con el tratamiento del análisis cualitativo de una muestra. Al respecto, la autora establece que este tipo de análisis debe abordar tanto los tipos y funciones que desempeñan las unidades morfosintácticas pesquisadas como los tipos de errores que comete un niño. Lo anterior es ejemplificado mediante el análisis de la producción de lenguaje por parte de un niño de 5 años 4 meses, en una actividad de recontado de una narración. El análisis realizado nutre un informe, que se presenta a modo de ejemplo, que da cuenta del desempeño del niño en el ámbito morfosintáctico expresivo, desde un prisma cualitativo. En relación al análisis cuantitativo de una muestra de lenguaje, la autora centra su atención en índices de medida como el promedio de longitud del enunciado (PLE), índice de complejidad sintáctica, índice de gramaticalidad, entre otros.

Si bien los análisis presentados en esta sección representan una forma de abordar el estudio de la morfosintaxis que está profundamente arraigada en la práctica fonoaudiológica, estos, probablemente, disipan la ilusión del lector de encontrar una propuesta de análisis refrescante, novedosa y atrevida. Una implícita insinuación en el título del manual despierta dicha ilusión. Personalmente, en esta tercera sección, esperaba encontrar una propuesta de análisis morfosintáctico abastecida, por ejemplo, por propuestas de las dos últimas décadas, que emanan de la lingüística de corpus y principios que sustentan la teoría constructivista sociopragmática del desarrollo del lenguaje, en particular, en los supuestos del modelo basado en el uso (Diessel, 2019; Lieven, 2014; Matthews \& Tomasello, 2008; Tomasello, 2000, 2003; 2011). Del mismo modo, la riqueza que ofrece un corpus de lenguaje oral invita al lector a estar expectante respecto de conocer, mediante un manual de morfosintaxis que aborda el análisis de muestras de lenguaje oral, acerca de fenómenos que comúnmente no son considerados en una pesquisa morfosintáctica en el ámbito de la fonoaudiología. Un fenómeno que esperaba encontrar en este manual, por ejemplo, tiene que ver con la sintaxis de enunciados en el marco de la macrosintaxis (Fuentes Rodríguez, 2017; Iglesias Bango, 2018). Lamentablemente, la espera continúa.

La última sección de la obra, Conclusión, ofrece las reflexiones finales por parte de la autora, respecto del análisis de muestras de lenguaje en el ámbito fonoaudiológico. Así mismo, en esta sección, se explicitan dos objetivos sobre los que se edifica el manual: "acercar al lector al análisis de las muestras de lenguaje espontáneo o dirigido" y "motivar al lector a la investigación, de manera de aportar datos sobre el desarrollo morfosintáctico de los niños y niñas de Chile o de habla hispana". Si el manual aquí reseñado consigue los objetivos presentados en esta sección, no cabe duda de que este habrá contribuido positivamente al desarrollo del conocimiento disciplinar, en general, y del andamiaje morfosintáctico aplicado al ámbito de la fonoaudiología, en particular.

A modo de conclusión, Manual de morfosintaxis: una propuesta de análisis del lenguaje desde la fonoaudiología es una obra que, por sus características, constituye un material de consulta, principalmente, para estudiantes de fonoaudiología que están iniciando su formación en el ámbito de la morfosintaxis. Sin 
embargo, se recomienda complementar el uso de este manual con materiales que orienten y promuevan la observación de los diversos fenómenos morfosintácticos posibles de evidenciar en una muestra de lenguaje oral, considerando los aspectos pragmáticos y comunicativos que, sin duda, modelan y explican el uso de construcciones morfológicas y sintácticas de variado nivel de abstracción y complejidad; un complemento de esta naturaleza o de otra que contribuye positivamente a profundizar el conocimiento acerca de los rasgos propios que definen el desarrollo típico, atípico y uso de la morfosintaxis en la infancia.

Reitero mi gratitud y manifiesto mis felicitaciones a la autora por ser parte del generoso movimiento que promueve, con acciones concretas, la recuperación del sentido público del conocimiento.

\section{REFERENCIAS}

Diessel, H. (2019). The grammar network: How linguistic structure is shaped by language use. Cambridge: Cambridge University Press. https://doi.org/10.1017/9781108671040
Fuentes Rodríguez, C. (2017). Macrosintaxis y lingüística pragmática. Círculo de

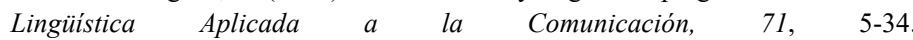
https://doi.org/10.5209/CLAC.57301

Iglesias Bango, M. (2018). Macrosintaxis: una propuesta sobre dimensiones, unidades y categorías. Círculo de Lingüística Aplicada a la Comunicación, 75, 19 44. https://doi.org/10.5209/CLAC.61345

Lieven, E. (2014). First language development: a usage-based perspective on past and current research. Journal of Child Language, 41(S1), 48-63. https://doi.org/10.1017/S0305000914000282

Matthews, D., \& Tomasello, M. (2008). Grammar. En J. Benson (Ed.), Encyclopedia of Infant and Early Childhood Development (pp 38-50). Amsterdam: Elsevier.

Tomasello, M. (2000). First steps towards a usage-based theory of language acquisition. Cognitive Linguistics, 11(1-2), 61-82.

Tomasello, M. (2003). Constructing a language: A usage-based theory of language acquisition. Cambridge, MA: Harvard University Press.

Tomasello, M. (2011). Language development. En U. Goswami (Ed.), The WileyBlackwell handbook of childhood cognitive development (pp. 239-257). Oxford: Blackwell Publishing Ltd. 